\title{
Photonics teaching development at California Polytechnic State University
}

Daniel Wasche, Sean Jobe, Dennis Derickson, Xiaomin Jin

Daniel Wasche, Sean Jobe, Dennis Derickson, Xiaomin Jin, "Photonics teaching development at California Polytechnic State University," Proc. SPIE 9665, Tenth International Topical Meeting on Education and Training in Optics and Photonics, 966526 (3 June 2007); doi: 10.1117/12.2207922

SPIE Event: Tenth International Topical Meeting on Education and Training in Optics and Photonics, 2007, Ottawa, Ontario, Canada 


\title{
Photonics Teaching Development at California Polytechnic State University
}

\author{
Daniel Wasche, Sean Jobe, Dennis Derickson, and Xiaomin Jin, \\ Electrical Engineering Department, California Polytechnic State University, San Luis \\ Obispo, CA 93407, Email: ddericks@calpoly.edu and xjin@calpoly.edu
}

California Polytechnic State University (Cal Poly) is one of 23 campuses comprising the California State University, the nation's largest four-year comprehensive public undergraduate university system. Cal Poly has a photonics program, photonics student club, and photonics laboratory within the Electrical Engineering Department that dates back to 1985. This laboratory is dual-use for both teaching and as a photonics center of excellence for the newly established Project-Based Learning Institute (PBLI) (http://pbl.calpoly.edu/). Our photonic education program at Cal Poly emphasizes four main educational tools. A. Lecture Classes. B. Photonics Laboratory Classes C. Student Photonics Club, and D. PBLI Design Projects. In this paper, we will describe the above four aspects with emphasizing on our new initiatives for part B and D.

Tool A, Lectures: We adopt multimedia course material in the lecture to match current fiber optic technology development.

Tool B, Photonics Laboratory Initiatives: Our primary goal in improving this laboratory was to replace old equipment (such as fusion splicer, ILX current sources), introduce modern components (e.g. SFP pluggable transceivers, Optical Amplifiers) and systems (1Gigabit Ethernet multimode and single mode links) to the fiber optic communication portion of the laboratory. We also are tightly linking hardware experiments with photonics simulation CAD tools (RSOFT product in our case). The lab instruction videos are also developed through out the years. These efforts demonstrate a more modern photonic lab experiments and meet current education goal.

Tool C, Student Photonics Club: Sponsored by SPIE since 1985, the club hosted the technical seminar given by both students and the outside speaker. It also organized field trip to Jet Propulsion Laboratory (JPL) in Jan 2007.

Tool D, PBLI Initiatives: The College of Engineering has formalized a mechanism that facilitates industrial and government sponsorship of engineering projects primarily for undergraduate students (PBLI). Through the PBLI program, students work with sponsor companies (such as Agilent and JDSU), internal or external research funding, and oversea research institute (Peking University, Beijing, China) under the guidance of professors. This paper will describe those photonics projects associated with PBLI and the benefits they provide to photonics education at the undergraduate level.

\footnotetext{
Tenth International Topical Meeting on Education and Training in Optics and Photonics, edited by Marc Nantel, Proc. of SPIE Vol. 9665, 966526 - () 2007 SPIE, OSA, IEEE, ICO doi: $10.1117 / 12.2207922$
} 